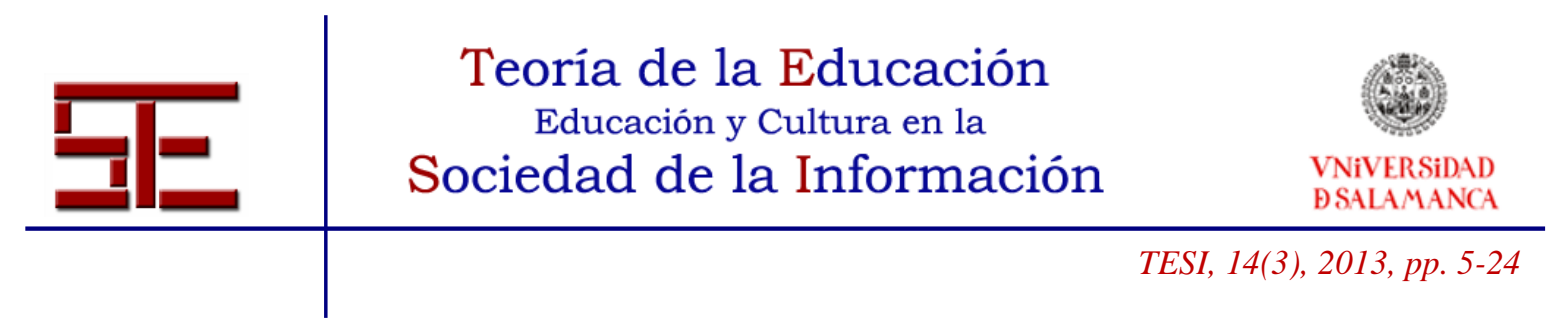

\title{
RECREACIÓN DEL ESPACIO EUROPEO DE EDUCACIÓN SUPERIOR EN EL HORIZONTE DE LA SOCIEDAD DE LA SABIDURÍA: HACIA UN NUEVO ESCENARIO DOCENTE
}

Resumen: El Espacio Europeo de Educación Superior (EEES) derivado del conocido proceso de Bolonia, ha llegado a su fin. No obstante, su instauración ha traído consigo la implantación definitiva de la no menos conocida Sociedad del Conocimiento y la democratización de las Tecnologías de la Información y la Comunicación (TIC) en el ámbito educativo. Todos estos cambios han sido imprescindibles para consumar el paso del saber al saber hacer y, con él, mejorar la calidad de la educación superior. En estas líneas replanteamos las características del mencionado cambio para tratar de comprender cuál podría, o debería, ser el siguiente objetivo a conseguir. De esta forma, abogamos por avanzar hacia una "Sociedad de la Sabiduría" que permita afianzar el conocimiento en postulados éticos y morales que nos ayuden a conseguir competentes profesionales, sin duda, pero también personas críticas y comprometidas que valoren, ante todo, el saber ser y estar.

Palabras clave: EEES, proceso de Bolonia, TIC, Sociedad de la Información, Sociedad del Conocimiento, Sociedad de la Sabiduría.

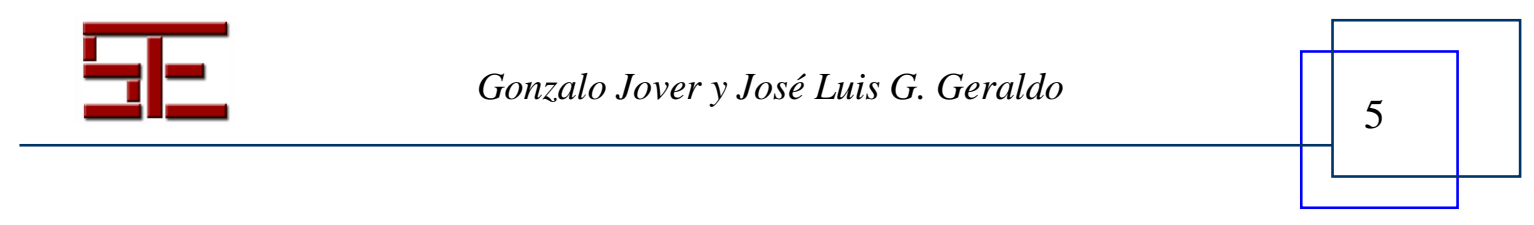




\title{
RECREATION OF THE EUROPEAN HIGHER EDUCATION AREA WITHIN THE HORIZON OF A WISDOM SOCIETY: TOWARDS A NEW EDUCATIONAL SCENARIO
}

\begin{abstract}
The European Higher Education Area (EHEA) derived from the well-known Bologna process, has come to an end. Nevertheless, its implementation has brought a sound introduction of the equally famous Knowledge Society and the democratization of the Information and Communication Technologies (ICT) in education. All these changes have been critical to consummate the step from the mere knowledge to the more desirable know how and, in this sense, improve the quality of higher education. In these lines, we would like to sum up the characteristics of the aforementioned change and try to understand what could, or should, be the next aim to be achieved. Therefore, we advocate moving towards a "Wisdom Society" that could allow to enhance knowledge on ethical and moral principles and help us to achieve competence-based professionals, no doubt about it, but also critical and committed people who would value, above all, knowing how to be.
\end{abstract}

Key words: EHEA, Bologna process, ICT, Information Society, Knowledge Society, Wisdom Society.

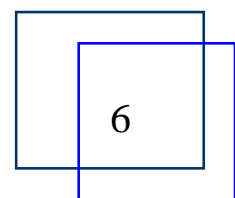




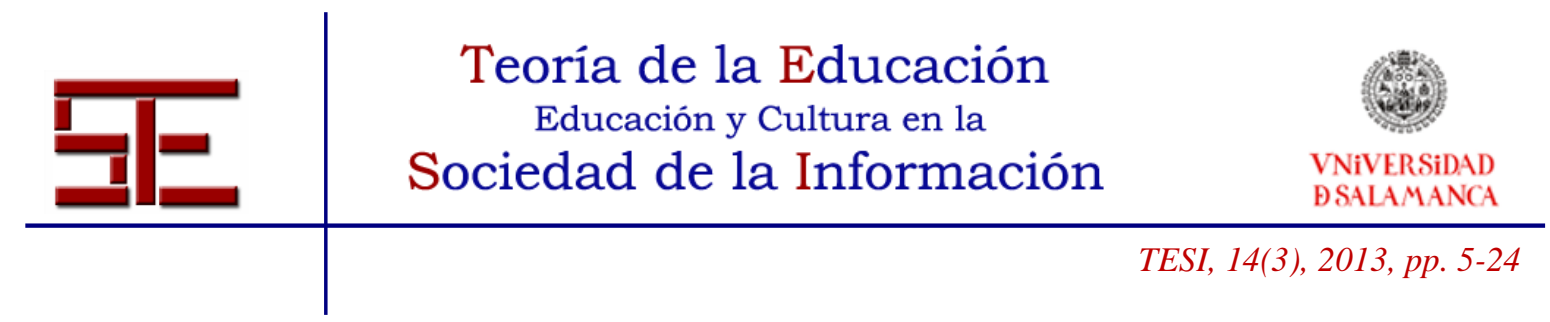

\section{RECREACIÓN DEL ESPACIO EUROPEO DE EDUCACIÓN SUPERIOR EN EL HORIZONTE DE LA SOCIEDAD DE LA SABIDURÍA: HACIA UN NUEVO ESCENARIO DOCENTE}

Fecha de recepción: 10/07/2013; fecha de aceptación: 19/09/2013; fecha de publicación: 30/11/2013

Gonzalo Jover

gjover@edu.ucm.es

Universidad Conmplutense

José Luis González Geraldo

JoseLuis.GGeraldo@uclm.es

Universidad de Castilla La Mancha

\section{INTRODUCCIÓN}

Ninguna innovación educativa es eterna. La implantación del Espacio Europeo de Educación Superior (EEEE) que ha pasado a conocerse como proceso de Bolonia, terminó formalmente en 2010 (Leuven Communiqué, 2009; Budapest-Vienna Communiqué, 2010) y, pese a que todavía siguen realizándose reuniones periódicas para estimar su impacto y eficiencia (Bucharest Communiqué, 2012) el interés que suscitó en su momento queda ya lejos. Pero la universidad es una institución histórica, viva. Es hora, por tanto, de preguntarse por las posibilidades de recreación de este proceso ¿Qué dirección tomarán los cambios que quedan por llegar? ¿Qué dirección deberían tomar?

Toda proyección al futuro implica alguna mirada al pasado. Aquí bastará con recordar que cuando se habla de los orígenes de las universidades modernas, sobre todo al referirse a las universidades europeas, suele aludirse a aquellas que nacieron en Italia y en Francia a partir del siglo XI, especialmente a las de Salerno, Bolonia y París, cada una de ellas relacionada específicamente con una profesión: medicina, justicia y teología, respectivamente. Recordando estos antecedentes, el filósofo y pedagogo escocés Simon Somerville Laurie afirmaba: "Podemos decir, entonces, que fue el desarrollo de las profesiones de la medicina, el derecho y la teología, lo que llevó a la inauguración y organización de la primeras escuelas superiores" (Laurie, 1891, p. 148).

No obstante, al tratar los inicios de la universidad es menos común referirse a los tiempos de la antigua ciudad de Alejandría y a la institución creada por uno de los generales del gran conquistador Alejandro: el Museum o templo de las musas. En la grandiosa biblioteca que se construiría a su alrededor y el Studium Generale anexo a la misma al que Tolomeo dotó de profesorado, encontramos el germen originario de la universidad (ibid., p. 44). Es curioso observar que si bien la presencia de la famosa biblioteca de Alejandría pudiera considerarse como un requisito sine qua non para

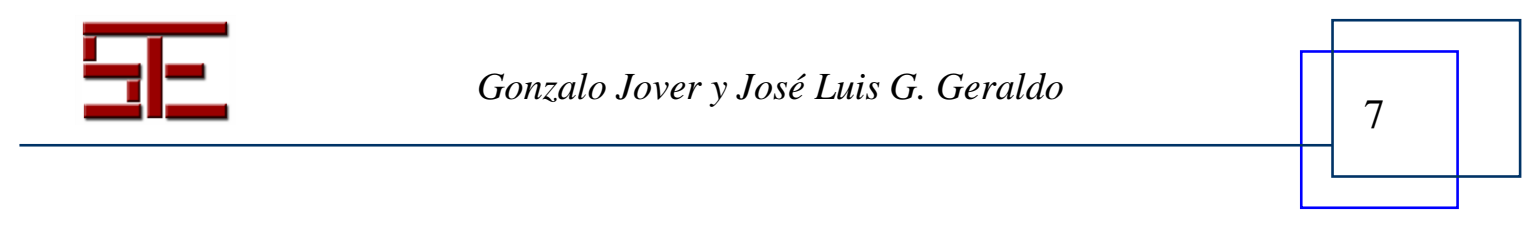




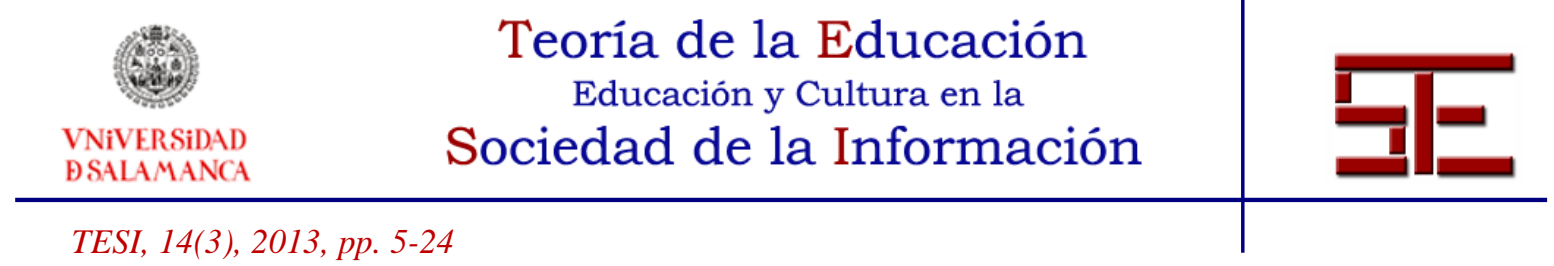

identificar las bases universitarias (Latorre Gaete, 1984, p. 36) no es un requisito suficiente. Como recordaba también Laurie, allí la enseñanza tenía un carácter más práctico y concreto que en Atenas, fomentado en buena medida por el cultivo de la medicina, las matemáticas y la gramática, lo que terminó por dar a Alejandría la preeminencia (Laurie, 1891, p. 45).

Se adopte un origen u otro, en ambos casos se detecta una orientación que va más allá de la mera información y pone el acento en la aplicabilidad práctica de los conocimientos, distinción que Sean Sturm adopta como eje de su propuesta en este número (Sturm, 2013). Por tanto, observamos cómo la universidad debe sus orígenes a la transformación de la información en acción, un aspecto que vuelve a resurgir, en una forma nueva, en los genes del EEES y su insistencia en la adaptación de la educación superior a las necesidades del mercado laboral, inserto en una economía internacional competitiva, en la que ser vencedor exige situarse en la primera línea de la carrera por el conocimiento.

Por otro lado, la irrupción de las potencialidades derivadas del uso de Internet no sólo ha transformado la ecología física de nuestras aulas, sino que también ha colaborado a transformar las funciones y los objetivos de las instituciones educativas, pues, como indica Vera en su contribución, "cualquier cambio en la tecnología de comunicación humana tiene efectos sobre el contenido de los mensajes que vehicula y sobre los modos y medios de pensar, reflexionar, expresarse, argumentar, recordar, etc." (Vera, 2013). La tarea que desempeñaba el sistema educativo al custodiar y trasmitir la información es ahora realizada por wikis y blogs. Ya no se trata de tener la información, sino de ser capaz de gestionarla para transformarla en conocimiento, un conocimiento que el estudiante debe construir de manera activa pues, en definitiva, lo que él hace es mucho más importante que lo que el profesor hizo, haga o llegue a hacer nunca (Shuell, 1986).

Mientras que la información y su transmisión siempre fueron uno de los principales objetivos de todo sistema educativo desde su aparición en el siglo XIX, la educación basada en competencias de nuestros días vuelve a enfatizar la necesidad de poner en práctica lo aprendido, de ser, en definitiva, un profesional "competente". El presente pertenece a la denominada sociedad del conocimiento. Sin embargo, el énfasis en pasar del puro saber al saber hacer puede hacernos perder de vista el no menos importante objetivo de ayudar a saber ser y estar (Delors, 1996, pp. 91-103). Este último saber identificaría un nuevo modelo de sociedad al que debe apuntar la educación del siglo XXI y que, frente a la sociedad de la información y del conocimiento, podemos llamar, siguiendo la graduación clásica de las formas de entendimiento (Savater, 1999) sociedad de la sabiduría. Como ha señalado Esteve, el conocimiento se convierte en sabiduría cuando se pone al servicio de la búsqueda del ser y el estar en el mundo (Esteve, 2010, pp. 117-118) aspiración que nos sirve como guía para avanzar hacia una universidad más humana (González Geraldo, 2013).

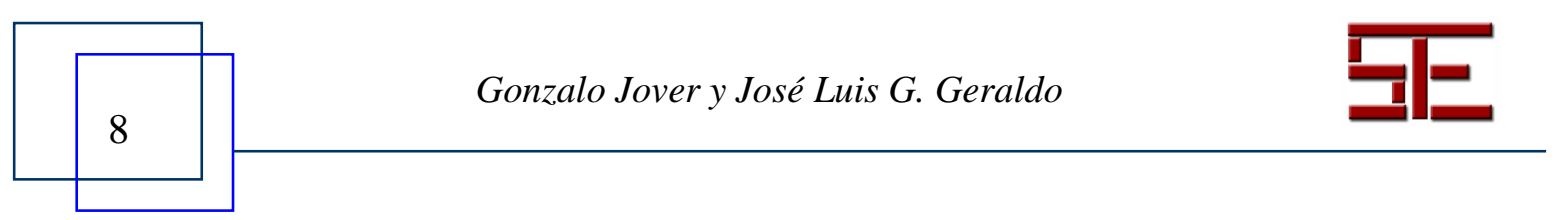




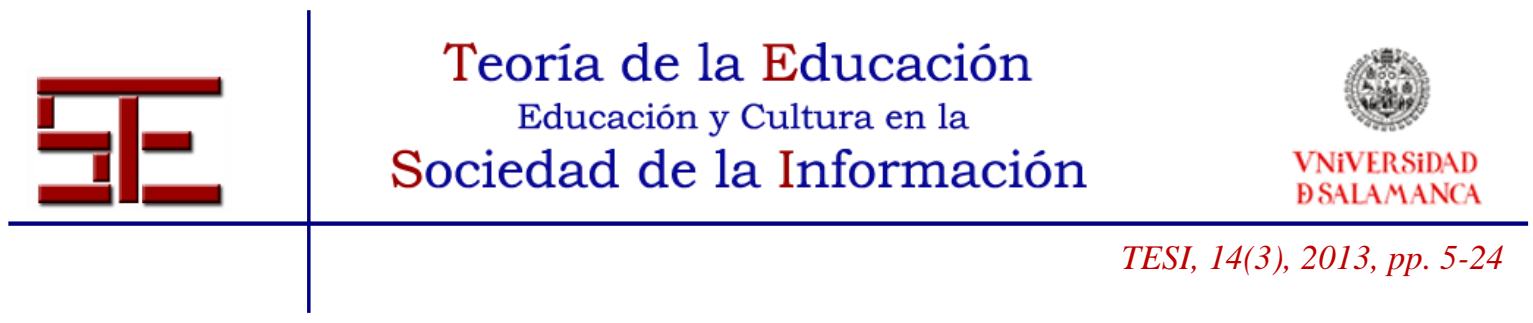

El presente trabajo se sitúa en este horizonte con un doble propósito: 1) analizar las potencialidades y los obstáculos que presenta el proceso de Bolonia desde un punto de vista pedagógico, y 2) debatir cuál sería la dirección adecuada a tomar en una recreación de dicho proceso. Para ello, lo estructuraremos en tres apartados. En primer lugar, expondremos los ejes de la orientación instrumental que guía el EEES en línea con las prioridades de la política educativa de la Unión Europea. A continuación, justificaremos la necesidad de avanzar desde la sociedad de la información y el conocimiento, en la que se instala el EEES, a la sociedad de la sabiduría. Para finalizar, extraeremos las implicaciones de este paso en la actividad docente y la preparación de los profesores universitarios.

\section{LA ORIENTACIÓN INSTRUMENTAL EN EL ESPACIO EUROPEO DE EDUCACIÓN SUPERIOR}

Como es sabido, los antecedentes del EEES se encuentran en la Declaración de la Sorbona, firmada el nueve de mayo de 1998, mediante la cual los Ministros de Educación de Francia, Alemania, Italia y Reino Unido se comprometían a impulsar "la creación de una zona Europea dedicada a la Educación Superior, donde las identidades nacionales y los intereses comunes puedan relacionarse y reforzarse para el beneficio de Europa, de sus estudiantes y en general de sus ciudadanos" (Sorbonne Communiqué, 1998). Un año más tarde, la iniciativa lanzada en París fue asumida formalmente por los Ministros de Educación de una treintena de países europeos reunidos en Bolonia, con la finalidad principal de hacer los sistemas de enseñanza superior más compatibles y comparables, favoreciendo la movilidad en el entorno europeo y la competitividad a escala internacional. Había nacido el proceso de Bolonia, que en sus concreciones subsiguientes se iría orientado más al logro de ciertos estándares que a una estandarización de los sistemas (Carter, Fazey, González Geraldo y Trevitt, 2010).

Aunque el EEES no es estrictamente una política de la Unión Europea, ésta asumió la iniciativa desde el objetivo estratégico, formulado en el Consejo Europeo de Lisboa en marzo de 2002, de "convertirse en la economía basada en el conocimiento más competitiva y dinámica del mundo, capaz de crecer económicamente de manera sostenible con más y mejores empleos y con mayor cohesión social" (Consejo Europeo de Lisboa, 2000). Este objetivo, que parecía anticipar las dificultades por venir, ha marcado la agenda de la política educativa durante la última década. Recientemente, por ejemplo, el Informe conjunto del Consejo y de la Comisión sobre la aplicación del marco estratégico para la cooperación europea en el ámbito de la educación y la formación (ET 2020) ha dejado claras las prioridades al señalar:

Es preciso modernizar los sistemas de educación y formación para aumentar su eficacia y calidad y dotar a las personas de las capacidades y competencias que necesitan en el mercado de trabajo,

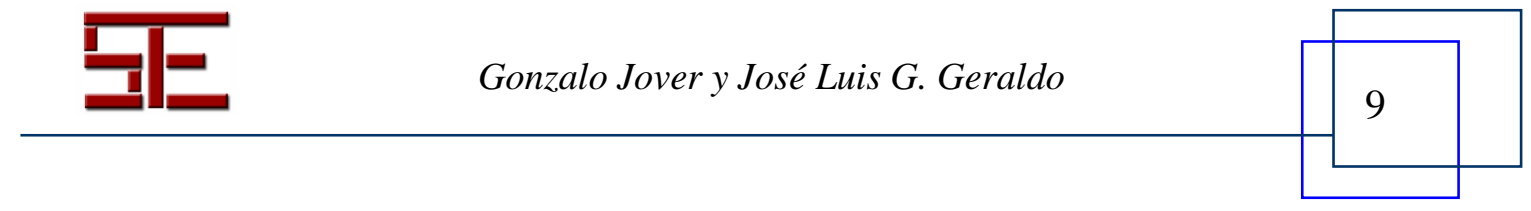




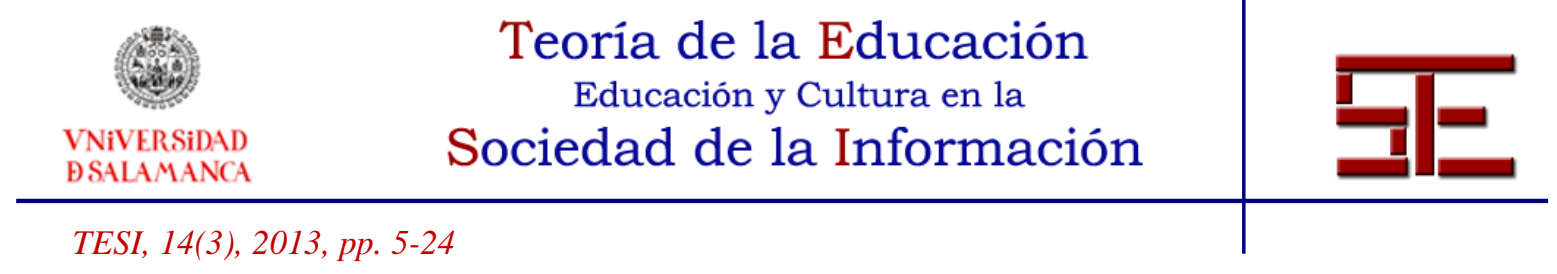

lo que aumentará su confianza para superar los retos actuales y futuros, contribuirá a aumentar la competitividad de Europa y generará crecimiento y empleo. (Unión Europea, 2012, p. 9).

Estas prioridades nutren el EEES, tal como puede verse en el sentido que adquieren dos de sus ejes centrales: la adopción del sistema de créditos ECTS y la alineación de la educación con el dominio de competencias profesionales.

El sistema ECTS, cuyas siglas corresponden a European Credit Transfer System, se adoptó inicialmente en 1989, en el marco del programa Erasmus, como instrumento para la transferencia de créditos, esto es un mecanismo que facilitase el reconocimiento de los períodos de estudio realizados en otros países, basado en el trabajo que lleva a cabo el estudiante en la institución de acogida. El proceso de convergencia hacia el EEES adoptó el ECTS como sistema ya no sólo de transferencia sino de acumulación de créditos, que sirviese para el reconocimiento de la actividad desarrollada en todos los niveles, institucional, regional, nacional o europeo, integrando procesos de formación en los ámbitos formal, no formal e informal (European Commission, 2002 y 2003).

Por una extraña conversión, en las universidades españolas el sistema ECTS dejó de tener un significado meramente administrativo, para transformarse en un principio pedagógico que parecía prometer la panacea educativa en cualquier contexto y circunstancia. ECTS se ha convertido en la fuente de apelación para justificar un cambio de metodología docente en el que el acento hay que ponerlo en el aprendizaje, en el estudiante y su actividad, más que en la enseñanza. Esta transmutación, pese a no ser tan novedosa como muchos creyeron, ha obligado a revisar las estructuras del trabajo universitario.

Ahora bien, ECTS refuerza el carácter paradójico del concepto de estudiante que subyace en el proceso del EEES, al que se han referido Bienefeld y Almqvis (2004). Por un lado, éste aparece como actor y partícipe de su formación, lo que supone una consecuencia adecuada de la consideración del estudiante como sujeto de su educación. Pero, por otro lado, ECTS puede fomentar también una visión clientelista del estudiante como consumidor que acumula, transfiere e invierte créditos, en función de las demandas del mercado laboral y una concepción instrumental del conocimiento, cuyo único valor es el del mercado.

Esta posible derivación alinea el sistema ECTS con ciertas tendencias que se van decantando en el panorama internacional, las cuales están produciendo un cambio en valores centrales de la cultura académica, como la excelencia, la libertad académica, o la idea de servicio público, que entran a menudo en conflicto con los objetivos enfocados a la rentabilidad económica inmediata:

Muchos estudiantes despliegan nuevos hábitos lingüísticos, con los significados consiguientes, tales como la noción inexpresada del estudiante como cliente y del profesor como abastecedor

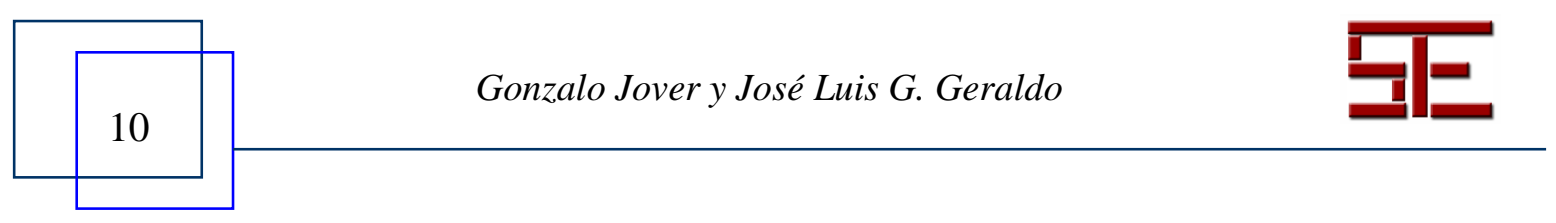




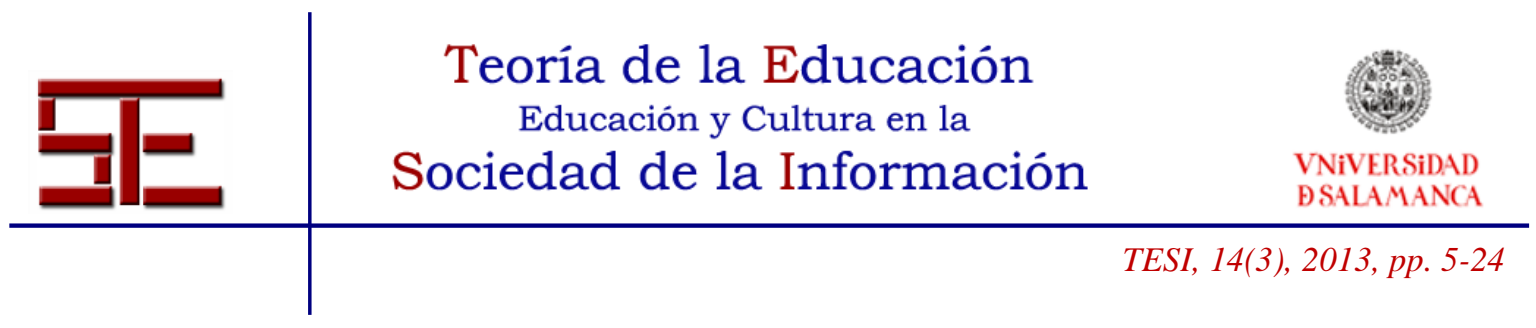

del servicio solicitado. Esta imagen traiciona la noción tradicional del aprendizaje centrado en el estudiante, pues el acento se pone en la capacitación del individuo en términos de competencias y alta destreza, y no ya en los términos académicos de una inteligencia crítica y reflexiva (BrunoJofré y Jover, 2008, p. 413).

La referida capacitación de los estudiantes en términos de competencias vinculadas a perfiles profesionales, es también uno de los requisitos de la adaptación de las enseñanzas al EEES. Como en el caso de la transformación de ECTS en un criterio metodológico, también aquí nos encontramos con una derivación no prevista en las intenciones originales del proceso, aunque coherente con la filosofía enfocada a la consecución de objetivos económicos.

Tal como recuerda García-Gutiérrez en su contribución a este número, emanado del ámbito de la formación y la gestión profesional, el concepto de competencia ha saltado -quizá asaltado- durante los últimos años al terreno de la educación en general, abriendo cuestiones que tienen que ver no sólo con el nivel de domino o uso, sino también con el de sentido (García-Gutiérrez, 2013). En España, esta idea ha encontrado algunos defensores, junto a un más numeroso grupo de férreos detractores, especialmente en el ámbito de la educación superior (Gimeno, 2008). Estos últimos consideran que una educación que pretenda preparar exclusivamente en el dominio de una serie de competencias definidas a partir de las necesidades laborales, deja de responder a los requerimientos de una auténtica formación integral y humanizadora (Jover, 2008). El discurso adopta, en consecuencia, ese carácter de confrontación entre una concepción alta, sublime, y otra baja, terrenal, de la educación, que se detecta también en otros contextos europeos (Tenorth, 2008) y que nos obliga a pensar qué hace que la educación superior sea, precisamente, superior (González Geraldo, en prensa).

En esta irreductible dualidad de concepciones late todavía hoy el viejo debate entre los partidarios de una orientación liberal de la enseñanza universitaria, y los partidarios de una orientación funcional. Debate que tuvo uno de sus momentos culminantes en la polémica que mantuvieron en los años treinta del siglo pasado Robert M. Hutchins, entonces Presidente de la Universidad de Chicago, y el pragmatista John Dewey, y que hoy parecemos abocados a reproducir (Jover y Gozálvez, 2012).

Hutchins criticó duramente la infiltración en la universidad del pragmatismo o instrumentalismo -como Dewey prefirió llamar a su filosofía- y su enaltecimiento de la función profesionalizadora y de la investigación científica, las cuales privan a "la universidad del único pretexto para su existencia, que es proporcionar un refugio en donde la búsqueda de la verdad pueda continuar sin trabas más allá de la utilidad o la presión por los "resultados"' (Hutchins, 1936, p. 43). Frente a esta situación, Hutchins abogaba por una formación general inicial, centrada en el cultivo de las virtudes intelectuales a través de los permanent studies y el contacto con los grandes libros de la tradición, tras la cual la universidad pasaría a ocuparse de las formas superiores de

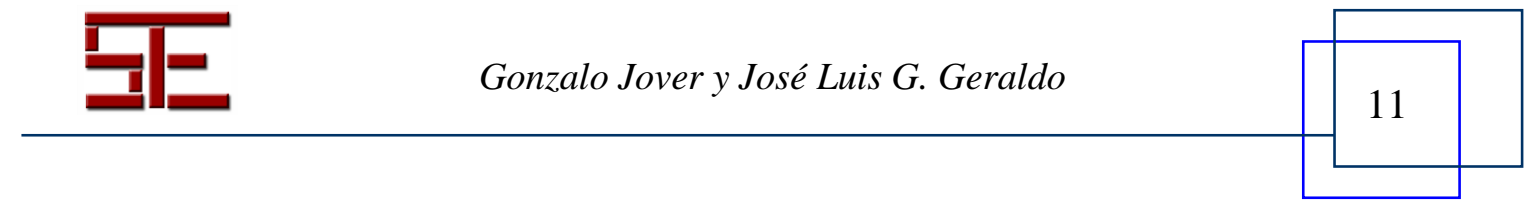




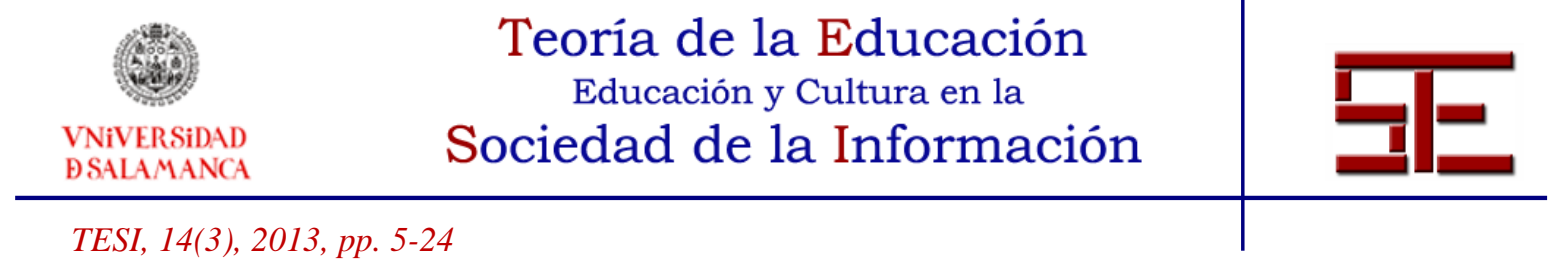

conocimiento, especialmente la metafísica, que son las que proporcionan una visión unificadora, por encima del caos provocado por el pragmatismo.

Para Dewey, la propuesta de Hutchins respondía a dos premisas erróneas: a) la creencia en la existencia de principios y verdades fijas y eternas y b) la necesidad de distanciar lo más posible la educación superior de la vida social contemporánea. Dewey llega a caracterizar esta concepción de autoritaria y presa fácil de posiciones fascistas:

Cualquier esquema que se base en la existencia de primeros principios fundamentales, con su dependiente jerarquía de principios subsidiarios, no escapa del autoritarismo al considerar tales principios como "verdades". No quisiera insinuar que el autor tiene alguna simpatía por el fascismo. Pero básicamente su idea de cómo ha de ser asumido el curso apropiado de las cosas es afín a una desconfianza en la libertad y a la correspondiente apelación a cierta autoridad fija que ahora está invadiendo el mundo (Dewey, 1937, p. 104).

En una reciente revisión del debate, Johnston ha señalado que no hay que extrañarse de que éste nunca fuese satisfactoriamente concluido (Johnston, 2011, p. 13). Quizás lo que se necesitaba era otro punto de mira, que permitiese ver la universidad como espacio no sólo de continuidad funcional con el mundo, como pretendía Dewey, ni sólo discontinuidad liberal, como quería Hutchins. Por decirlo con la fórmula unificadora que acuñó Pestalozzi, una universidad capaz de entender la educación como una imbricación de la mano y la cabeza, y ambas con el corazón.

Hoy menos que nunca se puede dudar de que la modernización de la educación superior tiene que poner su enorme potencial al servicio del crecimiento y la creación de empleo, como ha señalado la Comisión Europea en el marco de la iniciativa Europa 2020 (Comisión Europea, 2011). Pero tampoco nadie puede dudar de que la universidad debe apuntar más allá de la circunstancia actual, a la sociedad del futuro, con una mirada comprometida. Una mirada que requiere asumir la formación de personas, además de informadas y competentes, creativas y éticas, que tengan no sólo capacidad de ajuste, sino también de crítica y transformación. La universidad ha de facilitar el advenimiento de profesionales competentes, sin duda, pero también de personas que sean capaces de encontrar su mejor versión. Y, quizá, es aquí donde las propuestas asociadas al proceso de Bolonia y el aprendizaje por competencias resultan insuficientes y necesitan ser recreadas.

El cambio promovido por Bolonia sólo debería ser considerado como un paso más en nuestra búsqueda de la excelencia universitaria, que permita avanzar desde la sociedad de la información y del conocimiento hacia la sociedad de la sabiduría. En el apartado siguiente trazaremos el perfil de este cambio.

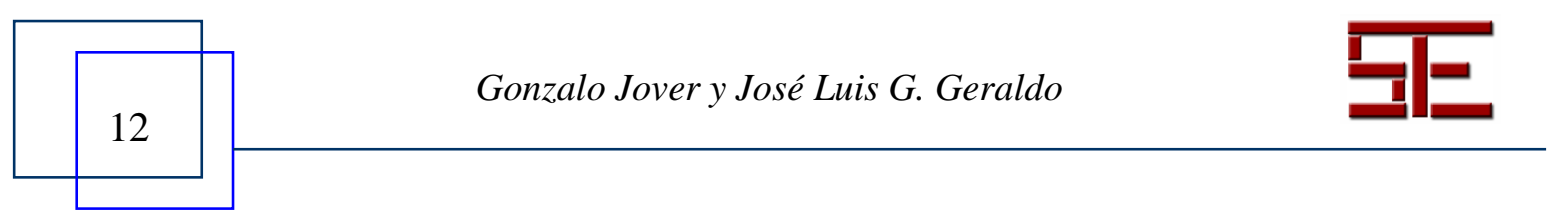




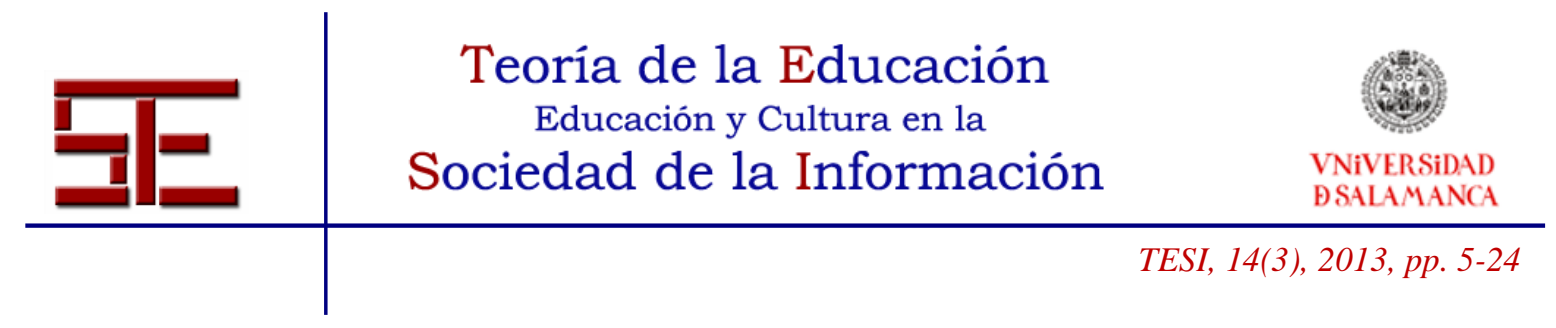

\section{DE LA SOCIEDAD DE LA INFORMACIÓN Y LA SOCIEDAD DEL CONOCIMIENTO A LA SOCIEDAD DE LA SABIDURÍA}

Hasta no hace demasiado, se acostumbraba a decir que vivíamos en la sociedad de la información, fruto del desarrollo y la expansión de las Tecnologías de la Información y la Comunicación (TIC). Sin embargo, hoy en día aceptamos que esta sociedad, propia del siglo pasado (Bell, 1973) está un tanto desfasada, y que el leitmotiv que la impulsó, "la información es poder", ha de ser matizado. La información sólo será poder si logramos convertirla en conocimiento. Romero y Gutiérrez, en su contribución al monográfico, y Barroso en la suya, inciden en ello. Los primeros son tajantes cuando afirman que la sociedad del aprendizaje, y la del conocimiento lo es, no puede identificarse sin más con una sociedad de la mera información (Romero y Gutiérrez 2013). En el mismo sentido, para Barroso "la difusión social de los instrumentos en que se funda la existencia de una sociedad de la información [...] no garantiza la constitución de una sociedad del conocimiento" (Barroso, 2013). Es preciso algo más. Se considera, así, que frente a la información, el conocimiento surge como una construcción perfectible y dinámica que otorga sentido y da contexto a la mera acumulación estructurada de datos (Ward y Peppard, 2006, p. 503).

En la sociedad del conocimiento, el saber (información) se logra por la acción con sentido en un contexto determinado, es decir, se convierte en saber hacer (conocimiento) la esencia del aprendizaje por competencias que postula el EEES. Ahora bien, como puntualizan Mínguez y Hernández en su artículo para este número, "en la sociedad del conocimiento late un hecho secreto que impulsa al hombre actual hacia una especie de un ir más allá, hacia algo nuevo" (Mínguez y Hernández, 2013). Es posible, de este modo, que con el énfasis dado a las competencias no se haya atendido suficientemente a ese "ir más allá", a las actitudes necesarias (saber ser y estar) para que la información y el conocimiento sean puestos al servicio del desarrollo individual y social. Un paso que no se produce de manera automática, y abre numerosos retos y paradojas que deben ser enfrentadas, tal como indican Burguet y Buxarrais con respecto a la unión entre las competencias derivadas de las TIC y el componente axiológico educativo (Burguet y Buxarrais, 2013). Según venimos sugiriendo, afrontar estos retos de forma que podamos superar los límites de la sociedad de la información y del conocimiento, requiere atreverse a mirar más lejos y avanzar desde la sociedad del conocimiento a la sociedad de la sabiduría, en línea con lo que han venido proponiendo durante los últimos años diversos autores (Blasi, 2006; Maxwell, 2007; Barnett y Maxwell, 2008; Marga, Berchem y Sadlak, 2008).

Podría parecer un anacronismo acudir a la vieja noción de sabiduría como horizonte de futuro del tipo de sociedad que debe inspirar el trabajo universitario. No lo es. La noción de sabiduría no es hermética. Como notó el filósofo existencialista Karl Jaspers, el conocimiento se logra, mientras que la sabiduría se persigue y se anhela, por lo que a

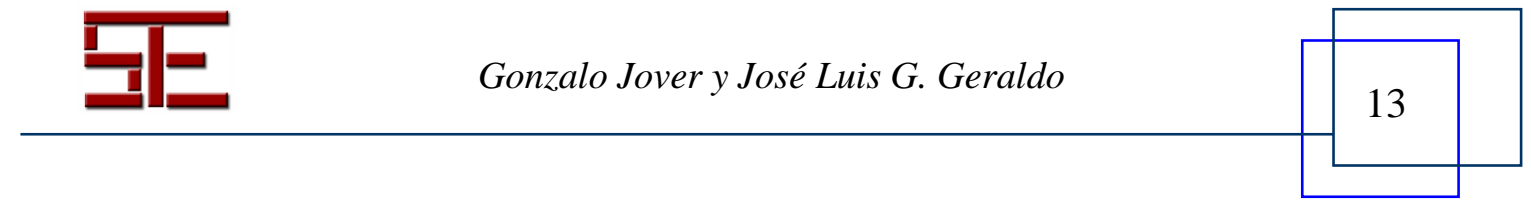




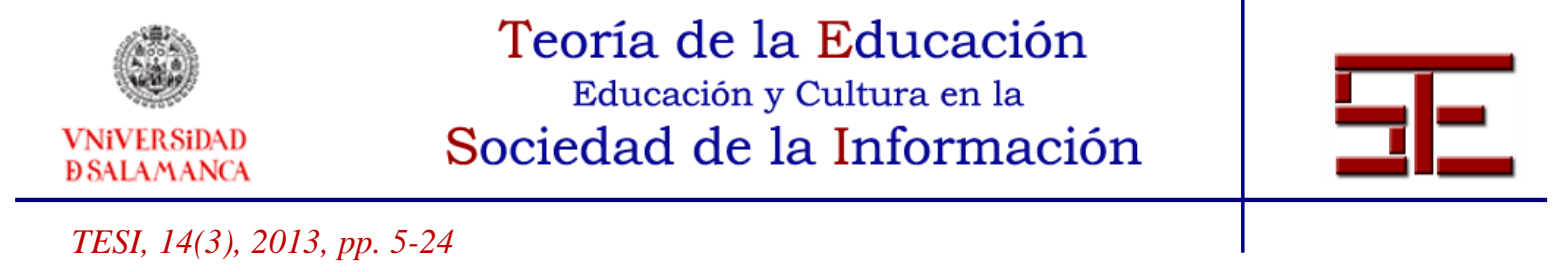

quienes la cultivan se les ha llamado con propiedad amantes del saber, filósofos (Jaspers, 2003, p. 12). La sabiduría consiste más en una permanente actitud de búsqueda que en un estado acabado.

En tanto que búsqueda, la sabiduría es la actitud más acorde con el estilo de la universidad como "un templo nunca concluido" (ibid. p. 164). Ahora bien, este sentido de la universidad, basado en la unidad del conocimiento científico y filosófico, como una obra en construcción, que todavía era evidente en el siglo XIX, añadía Jaspers, ha dejado de serlo: "La situación ha cambiado. Las ciencias se han fragmentado por la especialización. Se ha llegado a creer que el conocimiento científico, caracterizado por la pulcritud del universalmente válido conocimiento particular, podría desprenderse de la filosofía" (ibid.). La universidad parece de este modo abocada a lo que otro existencialista, Gabriel Marcel, llamó Le déclin de la sagesse (Marcel, 1954). La cuestión, por tanto, es si podemos volver a recuperar este ideal bajo unas condiciones nuevas.

En el debate al que nos hemos referido, Hutchins hacía responsables al instrumentalismo y el empirismo de ese déclin que, a su juicio, había sumido a la universidad en el caos, provocando la desarticulación del conocimiento bajo el primado de la experimentación y el progreso (Hutchins, 1936, pp. 25-26). La filosofía defendida por Dewey era el centro del ataque. Sin embargo, el propio Dewey, maestro en dar significados nuevos a conceptos viejos, apeló varias veces al ideal de sabiduría. En la conferencia que con el título Ethics, pronunció en mayo de 1908 en Columbia University, acudía a la antigua Grecia en la búsqueda de su significado, notando cómo la perspicacia de Platón al observar la riqueza del mundo social a su alrededor, le llevó a considerar que "la moral y la filosofía son lo mismo, a saber un amor a esa sabiduría que es la fuente de la seguridad y el bien social" (Dewey, 2003, p. 33). La sabiduría aparece aquí también como el objeto de un anhelo. Pero, añade Dewey, la mirada al pasado en busca de este ideal, que es tanto intelectual como moral, no puede quedarse allí, presa de sus limitaciones y ciega, por la pretensión de alcanzar un summum bonum incondicional, a los problemas y aspiraciones actuales y las soluciones ensayadas a lo largo de los tiempos:

\begin{abstract}
La moral, la filosofía, vuelve a su primer amor; el amor de la sabiduría que es nodriza, como la naturaleza es madre, del bien. Pero vuelve al principio socrático equipada con una multitud de métodos especiales de investigación y prueba, con un acopio organizado de conocimiento, y con el control de los mecanismos por los cuales la industria, la ley y la educación pueden concentrarse en el problema de la participación de todos los hombres y las mujeres, hasta su capacidad de absorción, en todos los valores logrados (ibid., p. 47).
\end{abstract}

Como capacidad moral y no sólo intelectual, la sabiduría ya no puede centrarse en una supuesta búsqueda desinteresada de la verdad. La parte mejor de ésta es la que tiene que ver con el interés, con la función práctica de lograr una vida y un entorno humano mejor. Su modelo ya no puede ser el del Beatus ille de quien se aparta de los negocios,

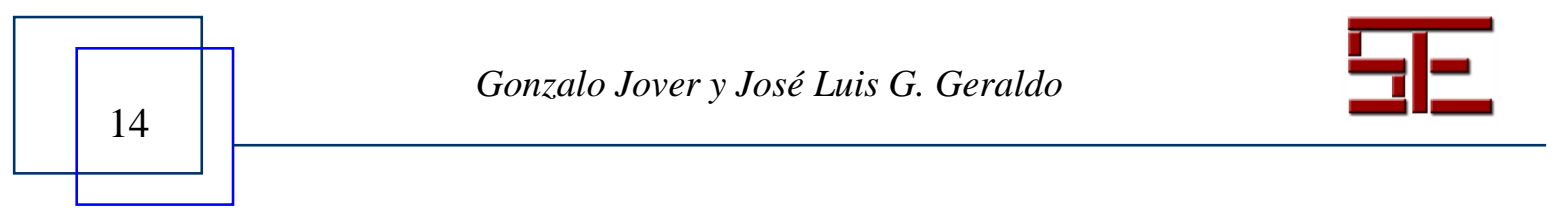




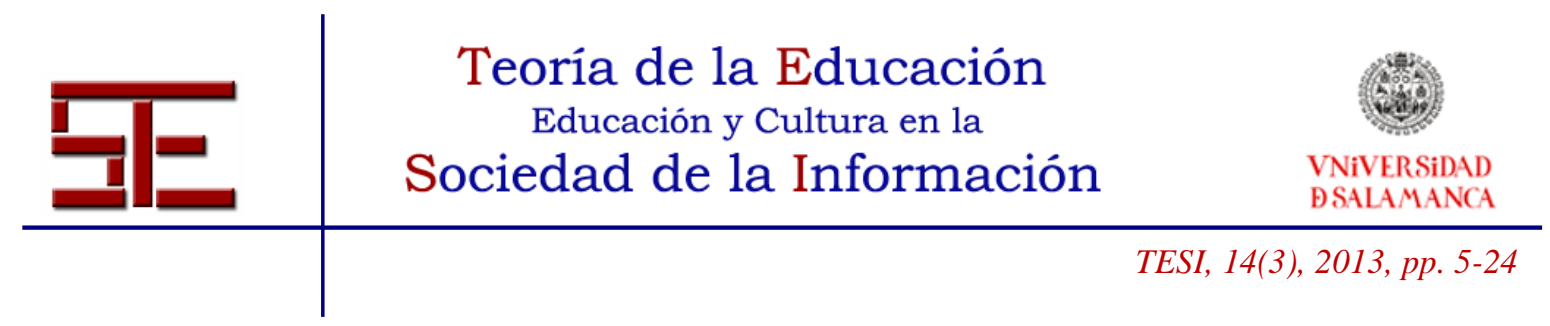

de Horacio (Epodos, 2, 1) ni el de la descansada vida de quien huye del mundanal ruido, de Fray Luis de León $(O d a, 1)$ ni el de la esjouissance constante de quien está como las cosas por encima de la luna, de Montaigne (Les Essais, libro I, capítulo XXV), ecos de formas de sociedad ya inexistentes. Ni siquiera su imagen puede ser la del cosmocentrisme del que hablaba Gabriel Marcel, desde el que "el verdadero objetivo del conocimiento y de la vida es integrarse en el orden universal, y en absoluto transformar el mundo llevándolo a la sujeción de la voluntad humana, de las necesidades y deseos del ser humano" (Marcel, 1954, p. 42). Esta actitud puede ser válida si significa la conciencia de un sentido de pertenencia universal que, como dice Hansen del cosmopolitismo, nos hace aprender "a equilibrar la apertura reflexiva a lo nuevo con la lealtad reflexiva a lo conocido" (Hansen, 2011, p. 1). Pero esa actitud ya no puede servir como modelo de sabiduría si se interpreta en el sentido de dar la espalda a las necesidades humanas que persisten en ese mundo, olvidando que "el mundo es lo que los seres humanos hacen de él, sujeto a las condiciones de su mortalidad, vulnerabilidad y falibilidad" (ibid., p. 6).

La sabiduría tiene que saber responder a las aspiraciones y circunstancias de su tiempo para, a partir de ellas, mirar más lejos, a lo que si bien no existe se perfila deseable en un mundo que depende de la voluntad humana y las acciones que de ella derivan, "porque nuestra sagacidad no sólo nos ha hecho capaces de ajustar medios a fines; nos ha capacitado para imaginar nuevos fines, para soñar en nuevos ideales" (Rorty, 2011, p. 13). La sabiduría ya no puede quedar encerrada en una pura actitud contemplativa, pero tampoco en una mera función de ajuste científico-técnico a lo dado, como si otras opciones no fuesen posibles. Si algo nos ha enseñado nuestra época es a desconfiar de las promesas de un progreso en el que, como la discípula de Jaspers, Hannah Arendt, criticó a Dewey, "la ciencia, y no el hombre, lleva la voz cantante" (Arendt, 2005, p. 243). Si pretendemos recuperar el ideal de la sabiduría como horizonte para la educación, el foco ya no puede ponerse sólo en el pasado, pero tampoco en la fe en el progreso científico por sí mismo. El acento hay que ponerlo en otro sitio: en el descubrimiento y atención al otro como un sujeto real.

\section{HACIA UN NUEVO ESCENARIO DOCENTE}

Avanzar hacia el horizonte diseñado requiere repensar la actividad docente y la preparación de los profesores universitarios, llamados a desempeñar una tarea al mismo tiempo sencilla y compleja. Sencilla, porque "el objetivo de la enseñanza es simple: hacer posible el aprendizaje del estudiante" (Ramsden, 2002, p. 7). Compleja, porque cada uno de nuestros estudiantes es tan único e irrepetible como sus sueños y potencialidades. La sociedad de la sabiduría actualiza la vieja idea de que el saber profundo es intrasmisible, debe ser alcanzado por uno mismo, pero ello no supone renunciar a la presencia del maestro, que sigue siendo irrenunciable. Las competencias

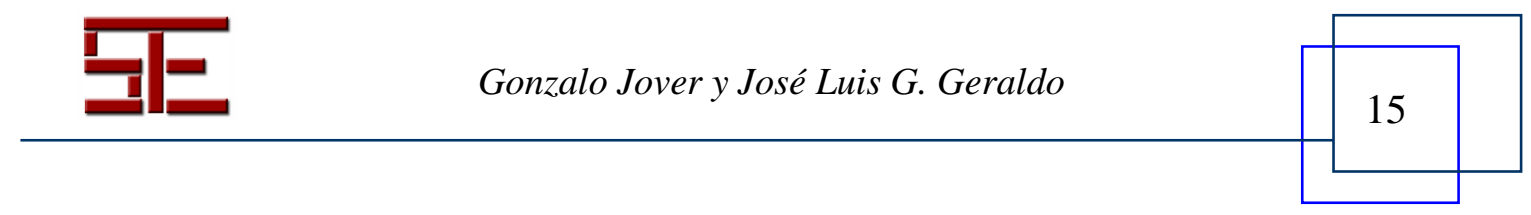




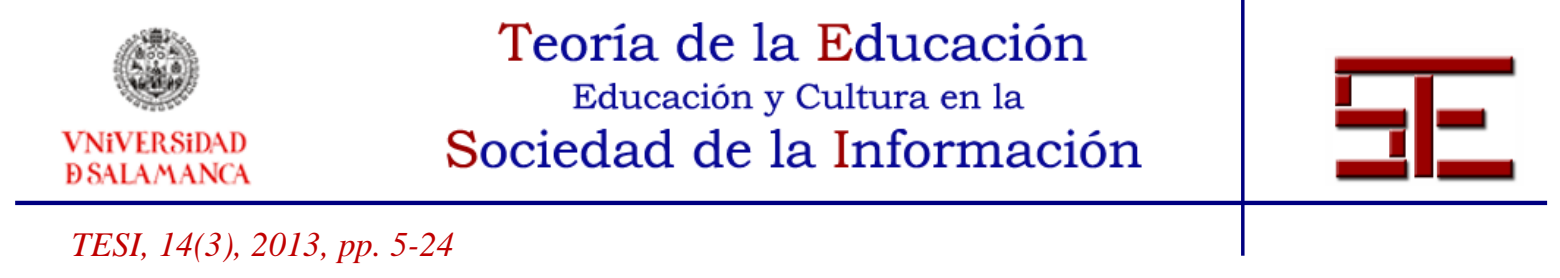

se pueden adquirir por procedimientos mecánicos. La sabiduría hay que verla encarnada en una vida.

A comienzos del siglo XIX Joseph Jacotot propuso su método de enseñanza universal, válido para enseñar cualquier cosa sin necesidad de apelar a un saber especial del maestro, bajo la presunción de que "tous les hommes ont une intelligence égale" (Jacotot, 1841, p. II). Para Rancière, estas ideas de Jacotot abren una vía de emancipación intelectual y política en la sociedad pedagogizada, la cual hace de la supuesta desigualdad inicial entre profesor y alumno su fuente de justificación (Rancière, 2010). Pero, en una lectura alternativa, la pretensión de un método universal de enseñanza, válido para cualquier tipo de contenido, abre también la vía hacia una mayor pedagogización formal de la relación entre el profesor y el estudiante. El ideal "democrático" de anulación de la autoridad del maestro en aras de la racionalidad formal del método, entraña las contradicciones del proceso de modernización tantas veces denunciadas, y que hoy vuelven a resurgir en algunas derivaciones que experimenta la noción del estudiante como centro de la educación, retomada e impulsada por el proceso de Bolonia. Nos referimos a las derivaciones que combinan esta centralidad del estudiante con elevadas cotas de planificación, que restan capacidad de acción a quien enseña y a quien aprende. De la pretensión de poner al estudiante en el centro, puede decirse, como Payne dijo de Jacotot, que "mucho puede ser logrado por este método en las manos de un maestro hábil, pero un charlatán podría convertirlo en una excusa para la ignorancia y la negligencia” (Payne, 1881, p. 62). Cabría hacer la misma observación con respecto a la integración educativa de las posibilidades tecnológicas en un mundo en el que, como sugiere Prats, la magnitud de los nuevos medios (wikis, blogs, Facebook, Twitter, etc.) pueden llegar a intimidar hasta al más seguro de los docentes (Prats, 2013). La clave está en recordar, advierten Argos y Ezquerra, que estas herramientas son precisamente eso: medios para alcanzar un fin más elevado, y que ante ellas lo más sensato debería ser desarrollar actitudes racionales, ni tecnofóbicas ni tecnofílicas (Argos y Ezquerra, 2013). De nuevo, la virtualidad educativa del método depende del talento pedagógico con que se usa.

Muchas universidades han emprendido programas de formación del profesorado inspirados en estratégicas metodológicas que respondan a lo que se supone son las exigencias del proceso de Bolonia: fomento de la actividad del estudiante, evaluación continua, uso de las tecnologías y los espacios virtuales, etc. Pero cada día es más evidente que ello no es suficiente. El nuevo escenario docente precisa una formación que evite los deslizamientos de los ejes de Bolonia a que nos hemos referido en el apartado anterior, y ayude a plantear de otro modo aspectos como la centralidad del estudiante y la preparación de los futuros profesionales.

Para que el lema del student-centrism no derive en clientelismo, tiene que compensarse con la capacidad de sentirse situado en un mundo allende la propia piel. Caben lecturas

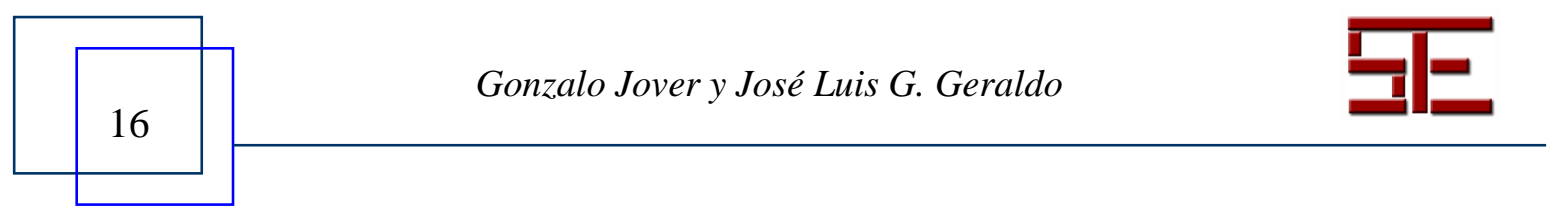




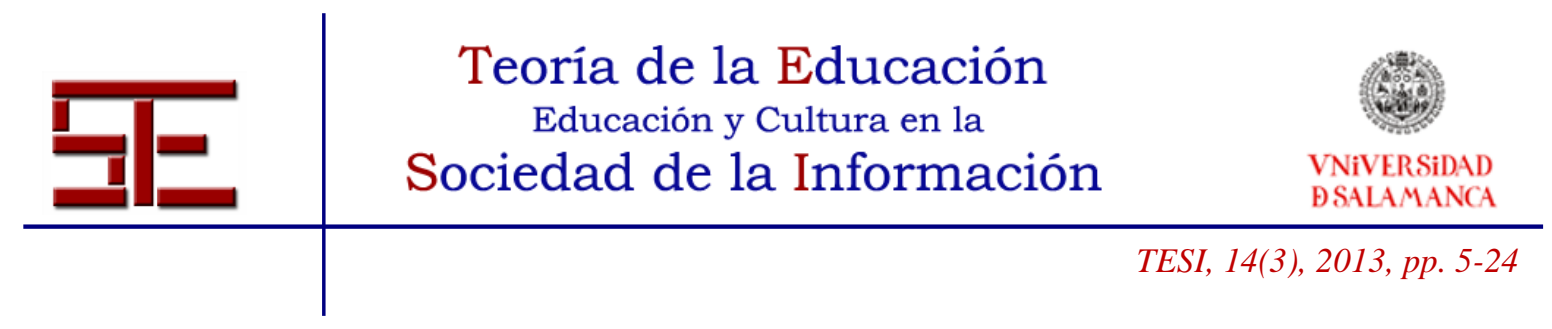

de ese lema que nos aproximan más a esta exigencia, como la que setenta años antes del proceso de Bolonia propuso Ortega y Gasset en Misión de la universidad (1930). Para Ortega, la necesidad de partir del estudiante nacía del principio de economía de la enseñanza, esto es, enseñar sólo aquello que el estudiante puede y debe aprender, lo que supone no sólo una reducción de los contenidos, sino un cambio de orientación:

El principio de economía no sugiere sólo que es menester economizar, ahorrar en las materias enseñadas, sino que implica también esto: en la organización de la enseñanza superior, en la construcción de la universidad, hay que partir del estudiante, no del saber ni del profesor. La universidad tiene que ser la proyección institucional del estudiante, cuyas dos dimensiones esenciales son: una, lo que él es, escasez de su facultad adquisitiva del saber; otra, lo que él necesita saber para vivir (Ortega y Gasset, 1982, p. 49).

Pero la perspectiva de Ortega era distinta a la que a menudo ha inspirado el lema de poner al estudiante en el centro formulado como derivación del proceso de Bolonia. Lo que justifica la economía de la enseñanza no es el menosprecio al saber carente de una utilidad inmediata, inconcebible en Ortega, sino, todo lo contrario, la necesidad de conjugar la preparación del profesional con una formación general más amplia que le permita estar a la altura de su tiempo y realizar desde ella su función social. Para ello, Ortega proponía la creación de facultades de cultura, que para él era el conjunto de ideas que en cada época permiten a los seres humanos orientarse en el mundo. Y ese conocimiento director de la vida es lo que, según Ortega, precisaba el ciudadano europeo prototípico o medio de su momento, encarnado en la figura del profesional, "más sabio que nunca, pero más inculto también" (ibid., p. 37).

Traducidas a términos actuales, las palabras de Ortega sugieren que, más allá de ciertas interpretaciones estrechas del principio de la centralidad del estudiante, la formación del profesorado universitario debe incluir también la capacidad para situar su campo de especialización en un horizonte de significación humana más amplio, desde el que provocar el descentramiento de los futuros profesionales y vencer esa tendencia al nihilismo que, según Charles Taylor, atenaza especialmente a los jóvenes universitarios (Taylor, 1994, pp. 93-94).

Una sociedad que aspire a la sabiduría no precisa que la mayoría de sus integrantes tenga mayores conocimientos eruditos de matemáticas y literatura; precisa más personas que sean capaces de leer el periódico de una manera distinta a la que lo leyeron el día anterior. En la sociedad de la sabiduría, la educación no se pone al servicio exclusivo de finalidades instrumentales, sino al servicio de cada estudiante para que llegue a sacar la mejor versión de sí mismo, para que encuentre su elemento (Robinson, 2009) y, así, halle en su propia autorrealización la mejor y más sincera manera de ayudar al bien de todos. La sociedad de la sabiduría no requiere embotar al estudiante con más conocimientos, sino provocar en él y en ella un cambio de mirada a sí mismo y al mundo.

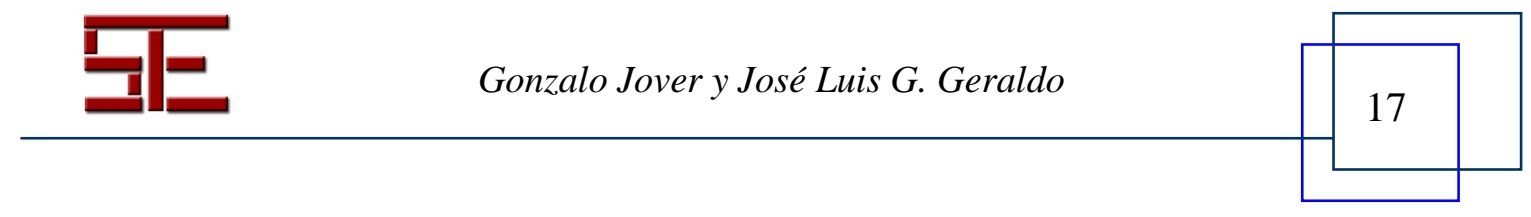




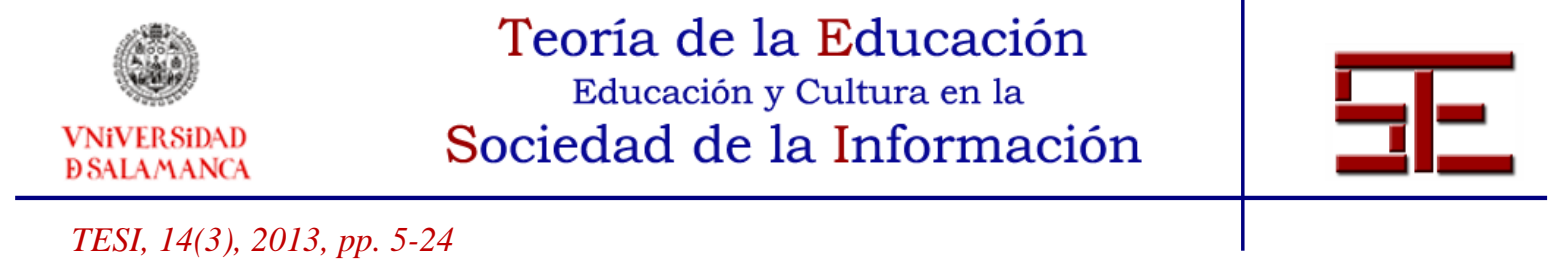

Se ha sugerido, en este sentido, la necesidad de corregir la preeminencia que ha adquirido el aprendizaje por competencias asociado al proceso de Bolonia, con perspectivas más holísticas, como la que representa, por ejemplo, el enfoque de las capacidades de Amartya Sen y Martha Nussbaum, en el que aspectos como los derechos humanos, la democracia y la sostenibilidad constituyen objetivos con entidad propia, y no sólo subproductos del aprendizaje instrumental (Lozano, Boni, Peris y Hueso, 2012, Walker, 2012). Para Nussbaum, la democracia como una aspiración no sólo política, sino también ética, requiere que, frente a una educación basada en el beneficio económico, situemos una educación que ayude descubrir al otro y a sí mismo con la profundidad con la que lo hacen la poesía y las artes, aunque, por supuesto, también éstas pueden ponerse al servicio de otros intereses, como analiza en este número Longueira con respecto a la enseñanza de la música (Longueira, 2013). Escribe Nussbaum:

\begin{abstract}
Concebir a los otros seres humanos como entidades amplias y profundas no es un proceso automático. Por el contrario, lo más fácil es ver al otro como apenas un cuerpo, que por ende puede ser usado para nuestros propios fines, sean éstos buenos o malos. Ver un alma en ese cuerpo es un logro, un logro que encuentra apoyo en las artes y la poesía, en tanto éstas nos instan a preguntarnos por el mundo interior de esa forma que vemos y, al mismo, tiempo, por nuestra persona y nuestro interior (Nussbaum, 2010, p. 139)
\end{abstract}

Según Nussbaum, en el desarrollo de estas capacidades resulta tan fundamental la acción de los entornos de pertenencia, la familia y los grupos de iguales, como lo que se enseña en las instituciones educativas, las escuelas y las universidades, y los métodos pedagógicos que en ellas se emplean (ibid., pp. 72-74). A través de su enseñanza y el empleo de los métodos pedagógicos adecuados, los profesores deben, así, ayudar a los estudiantes a ser profesionales competentes, capaces de transformar la información en conocimiento pero, sobre todo, ayudarles a ser personas críticas y comprometidas, dispuestas a colaborar, desde sus ámbitos de actividad, a crear un mundo en el que, empleando la fórmula kantiana, los demás sean vistos como fines y no sólo como medios.

La formación de los profesores no puede, por tanto, estar enfocada sólo a una preparación sobre qué y cómo enseñar o, por decirlo en los términos de Bolonia, cómo estimular la adquisición por el estudiante de una serie de competencias útiles para su futura actuación profesional. Esto es necesario, pero no suficiente. Ser un buen profesor implica algo más. En palabras de Hansen, "los buenos maestros golpean suavemente en la siempre ajetreada vida que late en los estudiantes, y les proporcionan ocasión tras ocasión para que experimenten por qué el currículo es, en sí mismo, una vibrante, siempre cambiante, respuesta a la vida" (Hansen, 2011, p. 124). El buen profesor muestra en el contenido de su enseñanza a quest for meaning, una búsqueda de sentido (ibid.) una exploración de respuestas nunca definitivas a los problemas que plantea la vida, problemas muchos de los cuales involucran, bajo su aspecto técnico, cuestiones de

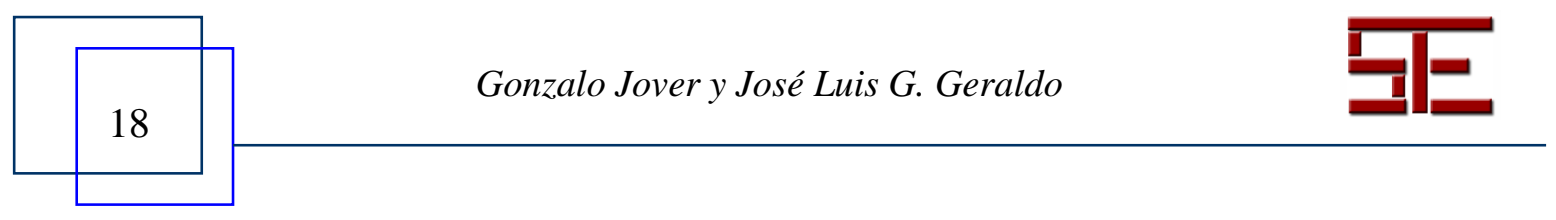




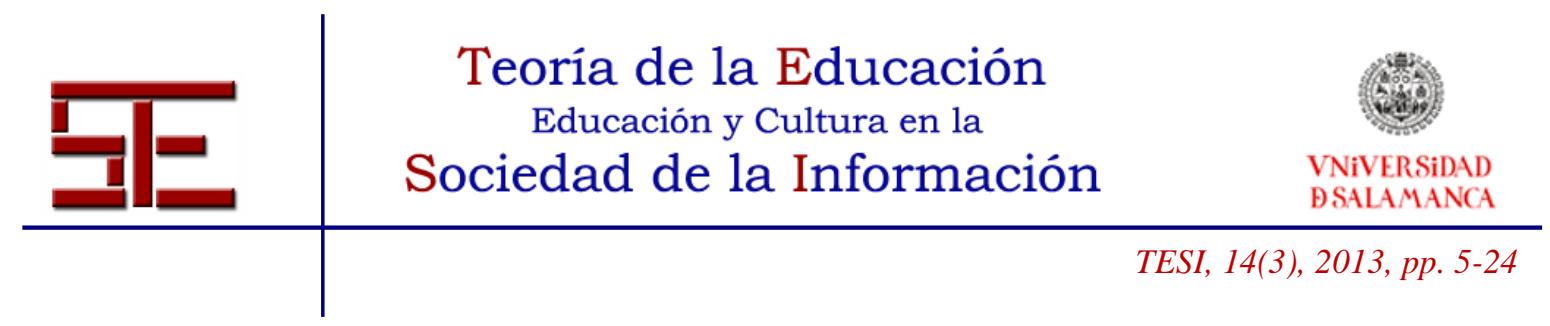

profundo significado ético y político. El buen profesor induce la actitud, en la que consiste la sabiduría, de interrogación ante la vida, una vida que no es una biografía solitaria, sino que nos compromete a todos y con todos como habitantes de un entorno común humano. Tal es el fundamento que da sentido a las demandas de introducir en el trabajo educativo la perspectiva de la sostenibilidad, como proponen en este número Aznar Minguet y Martínez Agut (2013). El profesor de universidad, cuyo trabajo consiste en vérselas cada día con el reto del conocimiento y el saber, está en una posición privilegiada para fomentar esa actitud de interrogación, con independencia de que trabaje en el campo de la humanidades y las artes o en el de las ciencias y los saberes técnicos. En un caso y en otro, tiene que contar con los recursos pedagógicos necesarios para estimular en los estudiantes la curiosidad, el interés y la disposición para ver su futuro ejercicio profesional no sólo como la aplicación de un conjunto de habilidades útiles, sino como una práctica de responsabilidad social que implica juicio y deliberación moral en un entorno de vida compartido.

La sociedad de la sabiduría es eminentemente utópica, no seremos nosotros quienes lo nieguen, pero necesariamente tiene que serlo, como cualquier ideal de futuro. No obstante, este razonamiento no implica tener que dejar de perseguirla desde la acción educativa, incluida la universidad. No deberíamos caer en lo que Sir Ken Robinson denomina la tiranía del sentido común (Robinson, 2010) y que hace referencia a la nada deseable actitud de pensar: "Así son las cosas, y no hay nada que yo pueda hacer". Si fuera cierto que nada puede cambiar, la educación carecería de justificación. Cada docente, con sus estudiantes, en sus clases, cada día, puede hacer mucho, puede marcar la diferencia de quienes, en breve, serán los empresarios, gobernantes, obreros, artistas o profesionales del mañana, formados para integrar su trabajo competente en un proyecto humano al servicio de un presente y un futuro mejores.

Pérez y López Francés refieren en su contribución al monográfico un estudio reciente, llevado a cabo en la Universidad de Valencia, sobre percepción de competencias docentes, el cual revela que los estudiantes consideran que las competencias personales del profesorado son las más importantes para valorar su profesionalidad (Pérez Pérez y López Francés, 2013). Quizá el paso más importante que debamos dar para encontrar el camino hacia la sociedad de la sabiduría sea entender que para tener buenos profesores debemos intentar que éstos sean, ante todo, profesores buenos.

\section{REFERENCIAS}

Arendt, H. (2005). La torre de marfil del sentido común. In Arendt, H.: Ensayos de comprensión, 1930-1954. Madrid: Caparrós, pp. 241-243.

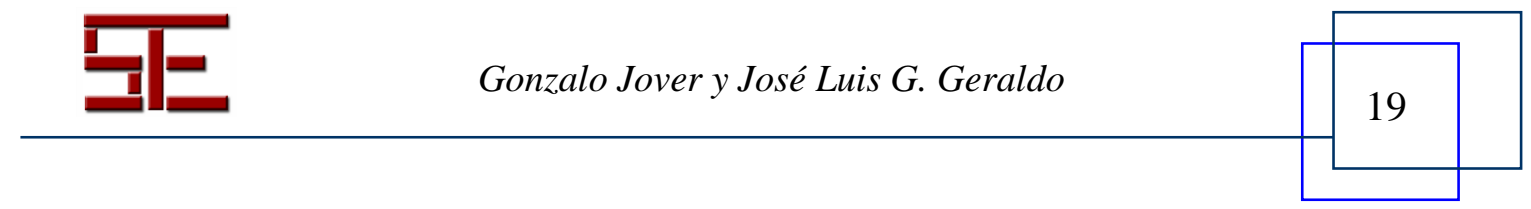




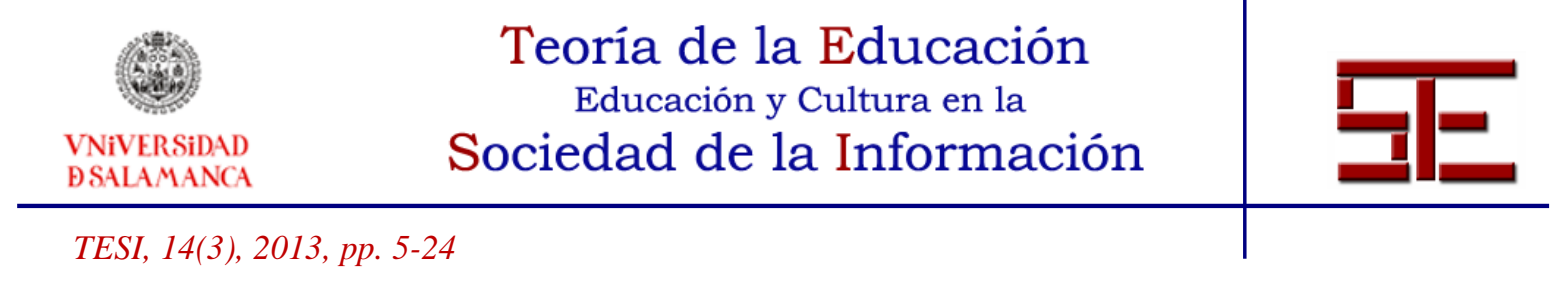

Argos J. y Ezquerra, P. (2013). Entornos hipertextuales y educación, Teoría de la Educación. Educación y Cultura en la Sociedad de la Información, 14 (3), en éste número.

Aznar Minguet, P. y Martínez Agut, M. P. (2013). La perspectiva de la sostenibilidad en la sociedad del conocimiento interconectado: gobernanza, educación, ética, Teoría de la Educación. Educación y Cultura en la Sociedad de la Información, 14 (3), en éste número.

Barnett, R. y Maxwell, D. (Eds.) (2008). Wisdom in the university. London, Routledge.

Barroso, C. (2013). Sociedad del conocimiento y el entorno digital, Teoría de la Educación. Educación y Cultura en la Sociedad de la Información, 14 (3), en éste número.

Bell, D. (1973). The coming of post-industrial society: A venture in social forecasting. New York: Basic Books.

Bienefeld, S. y Almqvist, J. (2004). Student Life and the Roles of Students in Europe, European Journal of Education, 39 (4), pp.429-441.

Blasi, P. (2006). The European university. Towards a wisdom-based society, Higher Education in Europe, 31 (4), pp. 403-407.

Bruno-Jofré, R. y Jover, G. (2008) Los estudios de formación docente y pedagógica en Canadá y España: cambios programáticos e institucionales en el escenario de internacionalización de la educación, Revista de Educación, 347, pp. 397-417.

Bucharest Communiqué (2012). Making the Most of Our Potential: Consolidating the European Higher Education Area. Communiqué of the Conference of European Ministers Responsible for Higher Education. Bucharest, 26 and 27 April. http://www.ehea.info/Uploads/\%281\%29/Bucharest\%20Communique\%202012.p df

Budapest-Vienna Communiqué (2010). Budapest-Vienna Declaration on the European Higher Education Area. Communiqué of the Conference of European Ministers Responsible for Higher Education. Budapest-Vienna, 12 ${ }^{\text {th }}$ of March. http://www.ehea.info/Uploads/Declarations/Budapest-Vienna_Declaration.pdf

Burguet, M. y Buxarrais, M.R. (2013). La eticidad de las TIC: Las competencias transversales y sus paradojas, Teoría de la Educación. Educación y Cultura en la Sociedad de la Información, 14 (3), en éste número.

Carter, S., Fazey, J., González Geraldo, J. L. y Trevitt, C. (2010). The doctorate of the Bologna Process third cycle: Mapping the dimensions and impact of the European Higher Education Area. Journal of Research in International Education, 9 (3), 245-258. doi: 10.1177/1375240910379383.

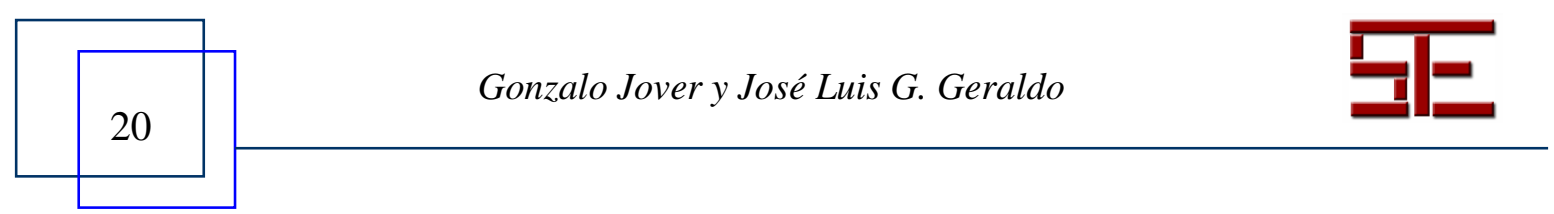




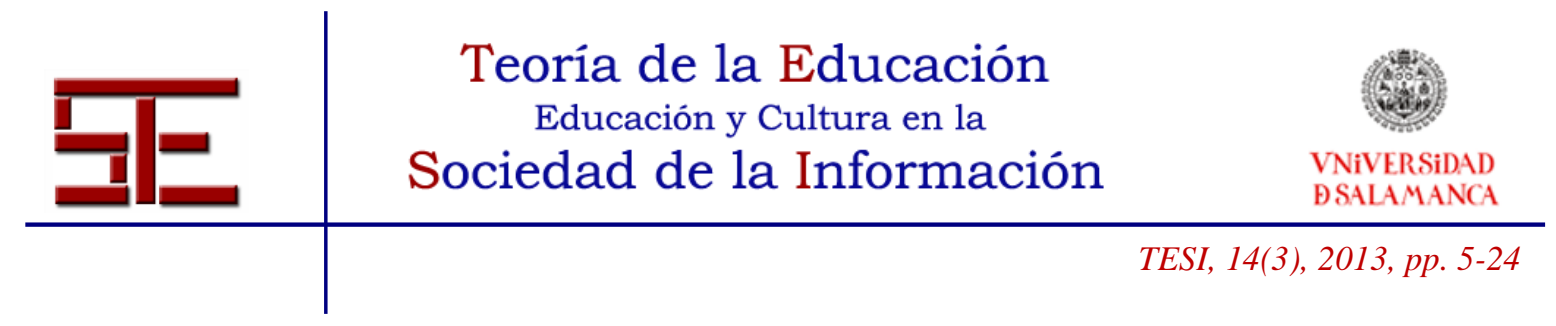

Comisión Europea (2011). Apoyar el crecimiento y el empleo - una agenda para la modernización de los sistemas de educación superior en Europa. COM(2011) 567 final.

Consejo Europeo de Lisboa (2000). Conclusiones de la Presidencia. Boletín de la Unión Europea, 3-2000.

Delors, J. (1996). La educación encierra un tesoro. Madrid: Santillana/UNESCO.

Dewey, J. (1937). John Dewey's Page: President Hutchins' Proposals To Remake Higher Education, Social Frontier, 3 (22), pp. 103-104.

Dewey, J. (2003). Intelligence and Morals. In: The Middle Works of John Dewey, 18991924. Electronic edition. Charlottesville: InteLex Corporation, vol.4, pp. 32-50.

Esteve, J.M. (2010). Educar: un compromiso con la memoria. Barcelona: Octaedro.

European Commission (2002). From Prague to Berlin. The EU Contribution. Progress report (Document $\mathrm{N}^{\circ}$ A2/PVDH, 1-8-2002)

European Commission (2003). From Prague to Berlin. The EU Contribution. Second progress report (Document $\mathrm{N}^{\circ}$ A2/PVDH, 15-2-2003-rev).

García Gutiérrez, J. (2013). Aproximación ética a la competencia digital. Los niveles de uso y sentido en ámbitos educativos virtuales, Teoría de la Educación. Educación y Cultura en la Sociedad de la Información, 14 (3), en éste número.

Gimeno, J. (Comp.) (2008). Educar por competencias ¿qué hay de nuevo? Madrid: Morata.

González Geraldo, J. L. (2013). Hacia una Universidad más Humana. Madrid: Biblioteca Nueva (en prensa).

González Geraldo, J. L. (en prensa). A la llum del Procés de Bolonya: ¿És superior l’educació superior? Revista Taula de Filología Valenciana.

Hansen, D. (2011) The teacher and the World. A Study of Cosmopolitanism as Education. London and New York, Routledge.

Hutchins, R. M. (1936). The Higher Learning in America. New Haven: Yale University Press.

Jacotot, J. (1841). Enseignement Universel. Langue Maternelle. Paris: Au Siège de l'Ecole de Jacotot

Jaspers, K. (2003). Way to Wisdom. New Haven: Yale University Press.

Johnston, J.S. (2011). The Dewey-Hutchins Debate: A Dispute over Moral Teleology. Educational Theory, 61 (1), pp 1-16.

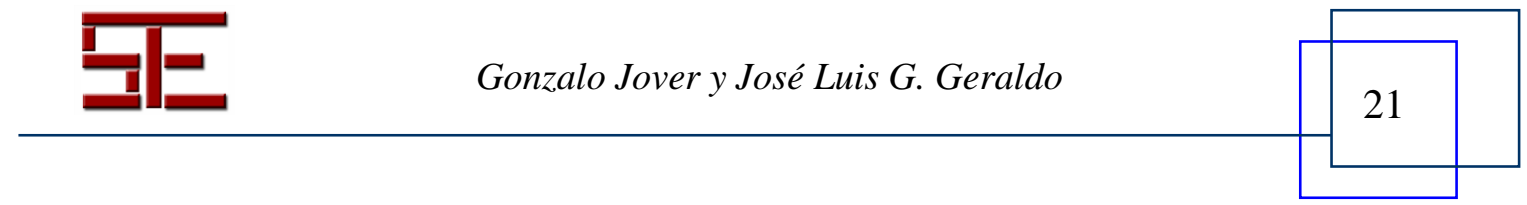




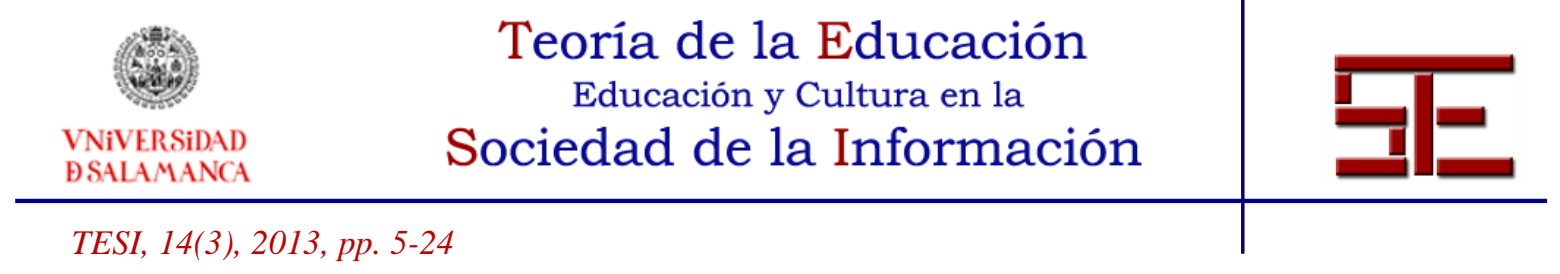

Jover, G. (2008). Bildung Versus Competencies: A View from the Gestation of Theoretical Knowledge of Education in Spain, Zeitschrift für Pädagogische Historiographie, 14 (1), pp.33-35.

Jover, G. y Gozálvez, V. (2012). La universidad como espacio público: un análisis a partir de dos debates en torno al pragmatismo, Bordón. Revista de Pedagogía, 64 (3), pp. 39- 52.

Latorre Gaete, E. (1984). El Museum de Alejandría: primera universidad en el mundo. Comunicación y Medios, 4, pp. 29-40.

Laurie, S. S. (1891). Rise and early constitution of universities. New York: Appleton and Company.

Leuven Communiqué (2009) The Bologna Process 2020: the European Higher Education Area in the new decade. Communiqué of the Conference of European Ministers Responsible for Higher Education, Leuven and Louvain-la-Neuve, 2829 April. http://www.ehea.info/Uploads/Declarations/Leuven_Louvain-laNeuve_Communiqu\%C3\%A9_April_2009.pdf

Longueira, S. (2013). Los retos educativos en la sociedad del conocimiento. Aproximación a las aportaciones desde el ámbito de la educación musical, Teoría de la Educación. Educación y Cultura en la Sociedad de la Información, 14 (3), en éste número.

Lozano, J.F.; Boni, A.; Peris, J.; and Hueso, A. (2012). Competencies in Higher Education: A Critical Analysis from the Capabilities Approach. Journal of Philosophy of Education, 46 (1), pp. 132-147.

Marcel, G. (1954). The decline of wisdom. London, The Harvill Press.

Marga, A.; Berchem, T. y Sadlak, J. (Eds.) (2008). Living in Truth. A Conceptual Framework for a Wisdom Society and the European Construction. Cluj-Napoca, Cluj University Press.

Maxwell, N. (2007). From knowledge to wisdom: the need for an academic revolution. London Review of Education, 5, pp. 97-115.

Mínguez, R. y Hernández, M.A. (2013). Hacia otra educación en la sociedad del conocimiento: cuestiones y propuestas pedagógicas, Teoría de la Educación. Educación y Cultura en la Sociedad de la Información, 14 (3), en éste número.

Nussbaum, M.C. (2010). Sin ánimo de lucro. Por qué la democracia necesita de las humanidades. Buenos Aires: Katz

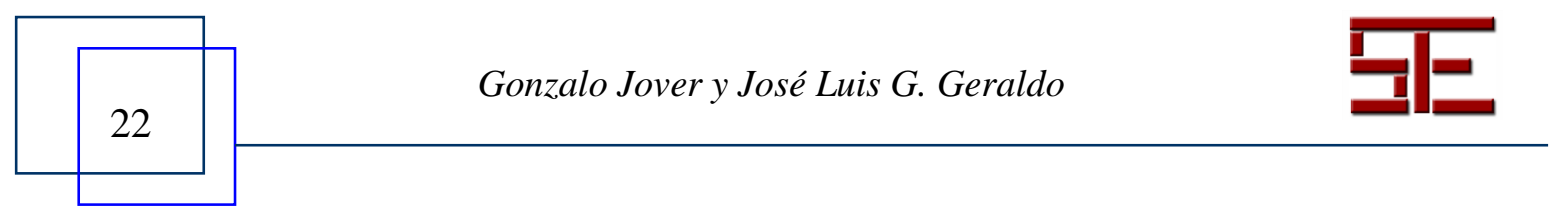




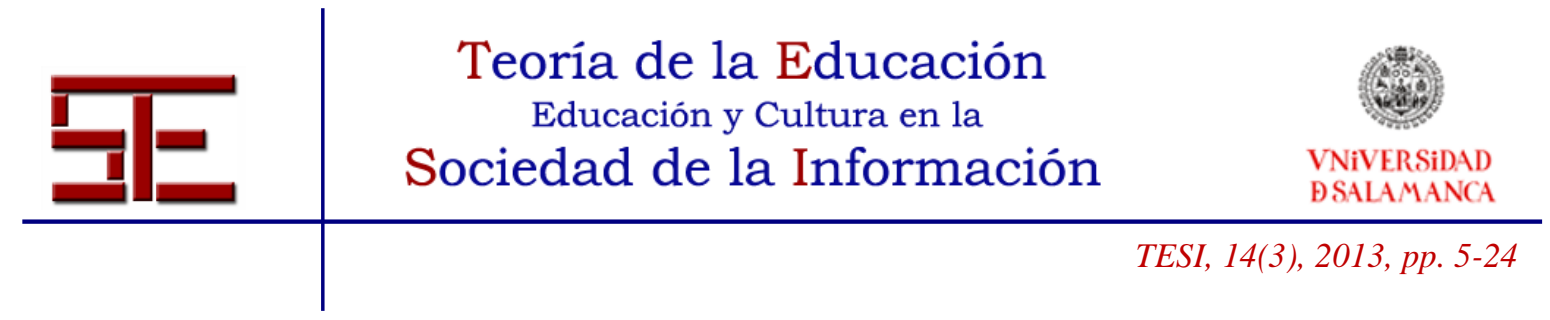

Ortega y Gasset, J. (1982). Misión de la universidad, en Misión de la Universidad y otros ensayos sobre educación y pedagogía. Madrid: Alianza / Revista de Occidente, pp. 11-79.

Payne, W. H. (1881). A Short History of Education. Syracuse: C.W. Bardeen.

Pérez Pérez, C. y López Francés, I. (2013) La percepción del alumnado sobre las competencias docentes del profesorado de la rama de Ciencias Sociales y Jurídicas de la Universitat de València, Teoría de la Educación. Educación y Cultura en la Sociedad de la Información, 14 (3), en éste número.

Prats, E. (2013). Jugando a ser dioses: puntos críticos de las tecnologías en la educación, Teoría de la Educación. Educación y Cultura en la Sociedad de la Información, 14 (3), en éste número.

Ramsden, P. (2002). Learning to Teach in Higher Education. London: Routledge.

Rancière, J. (2010). El maestro ignorante. Barcelona: Laertes.

Robinson, K. (2009). El elemento. Méjico: Grijalbo.

Robinson, K. (2010). Bring on the learning revolution! [Video]. Obtenido de http://www.ted.com/talks/sir_ken_robinson_bring_on_the_revolution.html

Romero, E. y Gutiérrez, M. (2013) Posibilidades y amenazas para que las actuales sociedades de la información se conviertan en verdaderas sociedades del aprendizaje y el conocimiento, Teoría de la Educación. Educación y Cultura en la Sociedad de la Información, 14 (3), en éste número.

Rorty, R. (2011) An Ethics for Today. New York: Columbia University, Press.

Savater, F. (1999). Las preguntas de la vida. Barcelona: Ariel.

Shuell, T. J. (1986). Cognitive conceptions of learning. Review of Educational Research, 56, 411-436.

Sorbonne Communiqué (1998). Joint declaration on harmonisation of the architecture of the European higher education system. http://www.ehea.info/Uploads/Declarations/SORBONNE_DECLARATION1.pdf

Sturm, S. (2013). Sophistry and philosophy: Two approaches to teaching learning, Teoría de la Educación. Educación y Cultura en la Sociedad de la Información, 14 (3), en éste número.

Taylor, C. (1994) La ética de la autenticidad. Barcelona, Paidós.

Tenorth, H.E. (2008). Bildungstheorie angesichts von Basiskompetenzen, Zeitschrift für pädagogische Historiographie, 14 (1), pp. 26-31.

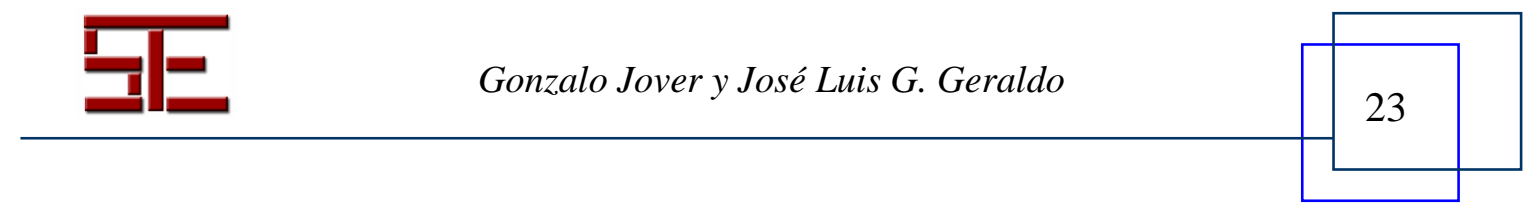




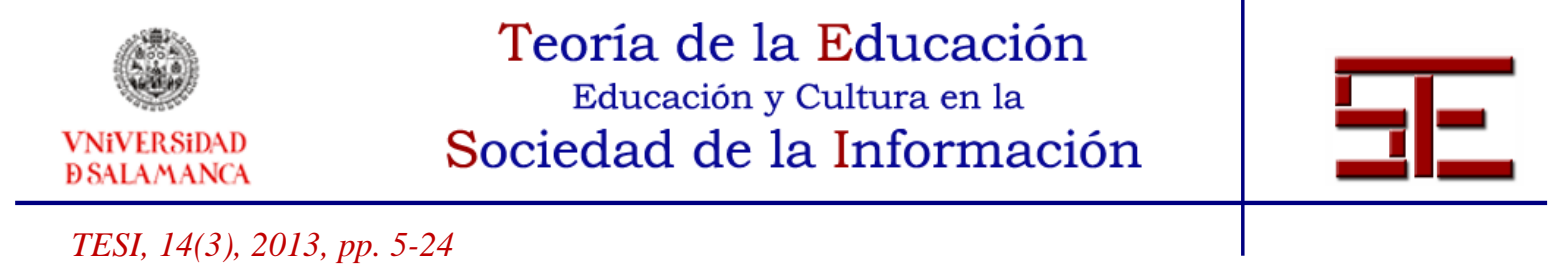

Unión Europea (2012). Informe conjunto de 2012 del Consejo y de la Comisión sobre la aplicación del marco estratégico para la cooperación europea en el ámbito de la educación y la formación (ET 2020) "Educación y formación en una Europa inteligente, sostenible e inclusiva”. DO C 70, 8.3.2012, pp. 9-18.

Vera, J. (2013). Primeros lenguajes y últimas tecnologías para la educación, Teoría de la Educación. Educación y Cultura en la Sociedad de la Información, 14 (3), en éste número.

Walker, M. (2012). Universities and a Human Development Ethics: a capabilities approach to curriculum, European Journal of Education, 47 (3), pp. 448-461.

Ward, J., y Peppard, J. (2006). Strategic Planning for Information Systems. Cranfield School of Management: Wiley and Sons.

Para citar el presente artículo puede utilizar la siguiente referencia:

Jover, G. y González Geraldo, J. L. (2013). Recreación del Espacio Europeo de Educación Superior en el horizonte de la sociedad de la sabiduría: hacia un nuevo escenario docente. Revista Teoría de la Educación: Educación y Cultura en la Sociedad de la Información. 14(3), 5-24 [Fecha de consulta: dd/mm/aaaa].

http://campus.usal.es/ revistas_trabajo/index.php/revistatesi/article/view/11347

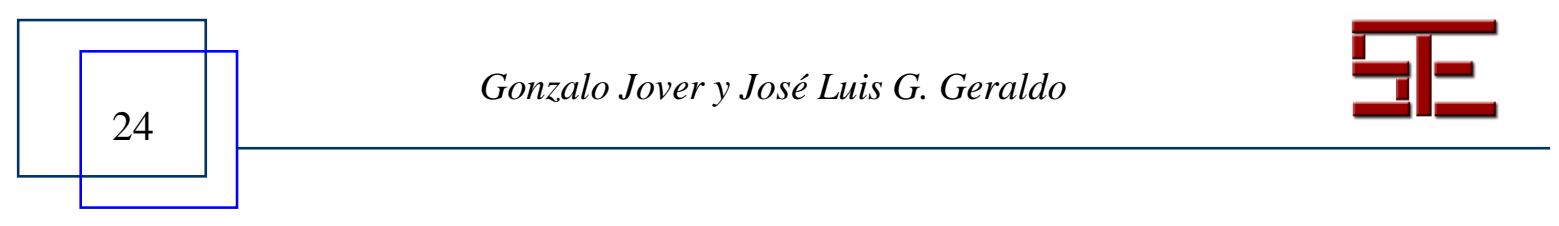

